\section{Nun also Flossing}

_ Trend über Trend. Was war gestern? Ich weiß es nicht mehr. Aber wenn wir mit neuen Verfahren Therapieziele besser erreichen, warum nicht? Vielleicht sind wir schon hintendran, wenn wir Ihnen in dieser Ausgabe der physiopraxis das Flossing vorstellen. Vielleicht praktizieren Sie es längst.

_ „Mittels Medical Flossing lassen sich nahezu alle akuten, subakuten und chronischen Schmerzzustände sowie Bewegungseinschränkungen - vorrangig an den Extremitäten, dem Thorax und dem Becken - positiv beeinflussen!", so unser Autor des Artikels auf S. 35 auf seiner Website.

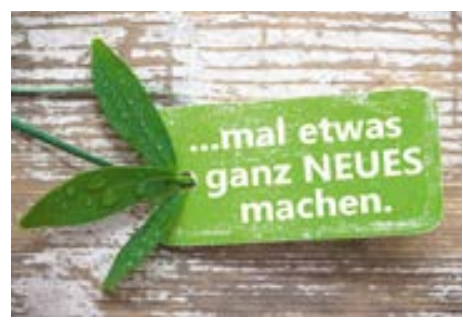

_ Woher kommt der Trend? Aus Amerika. Der amerikanische Physiotherapeut Dr. Kelly Starrett beschrieb Flossing in seinem Bestseller „Werde ein geschmeidiger Leopard“. Schon der Buchtitel ist ein Glücksversprechen. Starrett sprach von Voodoo Flossing. Voodoo beschreibt spirituelle Handlungen in kreolischen Glaubensgemeinschaften. Das „stramme“ Umwickeln der zu mobilisierenden Extremitäten mit einem Gummiband hat nichts Spirituelles. Wie der Kollege auf Voodoo kam, weiß ich nicht. Wissen Sie es?

_ Eines der Ziele ist, und so verstehe ich den Begriff Flossing, eine provozierte Gewebedurchspülung, deren Folgen Schmerzreduktion und bessere Beweglichkeit sind. Es gibt sehr gute Erfahrungen mit Flossing, die es durch wissenschaftliche Untersuchungen zu untermauern gilt. Neue Verfahren sind gut, und sie sind noch besser, wenn es Evidenz für ihre Wirksamkeit gibt.

_ Übrigens, wenn wir schon bei Trends sind: Die physiopraxis hat mit ihrem Erscheinen im Jahre 2003 einen Trend des Publizierens in der physiotherapeutischen Welt gesetzt. Freuen Sie sich heute schon auf die Januar-Ausgabe 2016. Die neue physiopraxis wird wieder ein Trendsetter sein, sie bekommt auch ein neues inhaltliches Konzept. Sie bietet Ihnen dann noch mehr Therapiewissen mit Hintergründen, Evidenz, konkretem Handlungswissen und jede Menge Know-how zum Weitergeben an Ihre Patienten. Und: Sie informiert Sie weiter über Trends.

Ihre

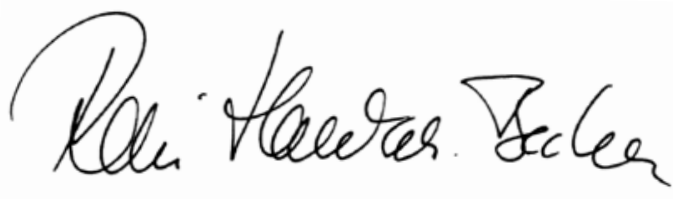

Neue Wege zu gehen, ist für Physiotherapeuten nicht neu.

\section{ZU GEWINNEN}

In jeder physiopraxis werden attraktive Gewinne verlost. Möchten Sie einen ergattern, klicken Sie unter www.thieme.de/physiopraxis auf „Gewinnspiel“.

Und das gibt es in dieser Ausgabe zu gewinnen:

Kurs

Zugang zum E-Learning-Kurs

„PNF“ Seite 32

und außerdem ...

3 CDs „Klassik

zur Entspannung“

Seite 40

1 Schädelbasis

mit Arterien

5 Teamaker 